\title{
CONSTITUCIONALISMO, DEMOCRACIA E A TENSÃO INSUPERADA: COMO A ADVOCACIA EM DEFESA DO CASAMENTO HOMOAFETIVO NOS ESTADOS UNIDOS SUPEROU A HIPÓTESE DO BACKLASH
}

\author{
CONSTITUTIONALISM, DEMOCRACY AND THE NEVER-ENDING TENSION: \\ HOW THE MARRIAGE EQUALITY LITAGATION IN THE UNITED STATES \\ OF AMERICA HAS UNDERMINED THE BACKLASH HYPOTHESIS
}

\author{
Alessandra Prezepiorski Lemos ${ }^{1}$
}

\section{RESUMO}

O presente trabalho optou por estudar o fenômeno do backlash e o seu impacto na litigância em matéria de casamento homoafetivo desenvolvida nos Estados Unidos. Através deste recorte, foi possível desconstruir algumas suposições a respeito da judicialização de demandas sociais. Demonstrou-se que os movimentos sociais não só levam em consideração a hipótese do backlash na hora de judicializar as suas demandas, como também fazem um uso positivo deste fenômeno. Ademais, explicitou-se que avanços e retrocessos fazem parte do jogo democrático, fazem parte da tensão existente entre Constitucionalismo e Democracia, sendo o backlash apenas mais uma parte desta disputa.

Palavras-chave: Backlash; litigância estratégica; casamento homoafetivo; direitos humanos; movimentos sociais.

\begin{abstract}
This paper aimed to carry out an analysis of the backlash phenomenon and its impact on the development of the marriage equality litigation in the USA. Through this methodological approach, it was possible to deconstruct some assumptions about the judicialization of social demands. It was proved that not only the social movements take into consideration the backlash hypothesis, but also that they make a positive use of it. Furthermore, it was showed that advances and setbacks are part of the democratic game, part of the tension between Constitutionalism and Democracy, and that the backlash is another part of this dispute.
\end{abstract}

Keywords: Backlash; strategic; marriage equality; human rights; social movements.

\footnotetext{
${ }^{1}$ Mestranda no Programa de Pós-graduação em Direito pela Universidade Federal do Paraná - UFPR, Paraná, (Brasil). Bacharel em Direito pela Universidade Federal do Paraná - UFPR, (Brasil).

E-mail: ale_lemos92@outlook.com
} 


\section{INTRODUÇÃO}

A relação entre Constitucionalismo e Democracia é, por si só, uma relação conturbada. Essa relação tem sido ainda mais tensionada pelo fato de que os movimentos sociais têm adotado progressivamente um discurso principalmente marcado por uma linguagem jurídica, como forma de reforçar a sua argumentação, e tem optado com maior frequência pela judicialização de suas demandas.

Dentro deste contexto, o fenômeno do backlash tem ganhado cada vez mais destaque na literatura acadêmica, pois a partir dele é possível problematizar a relação tensa entre Direito e Democracia, especialmente através da análise da dinâmica estabelecida entre Direito, movimentos sociais e mudanças sociais.

A hipótese do backlash, isto é, a proposição de que a litigância em matéria de direitos da minoria causa mais malefícios do que benefícios na busca por transformação social, tem sido apontada como um argumento contrário a essa crescente judicialização das demandas dos movimentos sociais.

Esta hipótese, entretanto, apresenta limitações quando confrontada com as estratégias jurídicas e políticas adotadas pelo movimento LGBT norte-americano na luta pelo reconhecimento legal do casamento homoafetivo.

Este movimento não só internalizou a hipótese do backlash, direcionando toda a sua atuação de forma a evitar tal fenômeno ou pelo menos diminuir sua intensidade, como também aprendeu a utilizar o backlash a seu favor, demonstrando como as mobilizações contrárias à causa podem acabar por fortalecer o movimento em prol do casamento igualitário.

O presente trabalho cuidará de examinar justamente a relação que o movimento LGBT estabeleceu com a hipótese do backlash, bem como demonstrar que o dissenso não é um problema per se, mas sim um elemento importante do jogo democrático. A metodologia utilizada foi a de revisão bibliográfica da literatura relevante para a temática, dando maior destaques às fontes norte-americanas já que afetas diretamente à discussão aqui travada.

Em um primeiro momento, este artigo irá apresentar a definição de backlash e explicar em detalhes o que seria a hipótese do backlash. Posteriormente, será analisado o impacto da narrativa do backlash na construção das estratégias de advocacia relativas à legalização do 
casamento homoafetivo, apresentando com maior destaque a estratégia da dual track advocacy criada por Evan Wolfson. A terceira parte, a seu turno, será dedicada a demonstrar as limitações da hipótese do backlash e a explicitar como o dissenso, mesmo quando provocado por decisões judiciais envolvendo direitos de minorias, é um aspecto importante do jogo democrático e pode, inclusive, servir ao avanço da agenda jurídica destas mesmas minorias. Ao final, serão apresentadas algumas conclusões a respeito do tema.

\section{A CONSTRUÇÃO TÉORICA DA HIPÓTESE DO BACKLASH}

Um dos grandes debates que circundam a advocacia na área de direitos humanos é se essa prática realmente pode levar a verdadeiras mudanças na realidade social ou se, ao contrário, ela seria ineficaz ou até mesmo prejudicial às causas que tanto visa defender e promover.

Em lugar de destaque nesta discussão está o que se convencionou chamar de hipótese do backlash, também conhecida por tese do backlash ou narrativa do backlash.

A hipótese do backlash, neste contexto, é apresentada por parte da literatura acadêmica como um forte argumento que demonstra como a litigância em matéria de direitos das minorias tem tido mais efeitos negativos do que positivos na proteção e promoção destes direitos.

Diante disso, indispensável se faz definir precisamente o que se entende por hipótese do backlash e porque alguns teóricos entendem que ela seria um atestado da inconveniência da adoção de estratégias judiciais na luta pela efetivação da justiça social.

A expressão backlash é definida pelo Dicionário Oxford como "uma forte reação negativa de uma quantidade considerável de pessoas a um acontecimento social ou político".

Vanice Regina Lírio do Valle, por sua vez, ressalta o aspecto reativo do que se intitula backlash ao afirmar que esta palavra "tem como significado primário um súbito e intenso movimento de reação, em resposta a uma mudança igualmente brusca na trajetória do movimento" (2013, p. 5).

A autora ainda frisa que, neste significado literal, o uso do prefixo back não quer transparecer necessariamente a ideia de regresso ou de retrocesso, mas sim reforçar que se trata de uma reação em sentido contrário, inverso (VALLE, 2013, p. 5). 
Quando o foco está nas deliberações emanadas do Poder Judiciário, a expressão backlash traduz a ideia de uma reação contrária, de uma expressiva resistência a uma decisão judicial (2011, p. 123).

Apesar de o conceito, a princípio, poder ser empregado para definir toda mobilização social contrária a uma manifestação do Poder Judiciário, o termo tem sido adotado para descrever as mobilizações sociais geradas por decisões judiciais progressistas, deliberações que implicaram em avanços em matéria de direitos e garantias concedidos às minorias.

O sentido ligado à ideia de retrocesso adquirido pela palavra backlash se deve ao fato de que ela inicialmente foi utilizada na arena política para descrever a resistência de setores da sociedade norte-americana contra o movimento dos direitos civis, movimento este que tinha como mote a promoção da igualdade racial entre brancos e negros (POST; SIEGEL, 2007, p. 17).

Desde então, a expressão backlash tem sido utilizada em contextos em que grupos desfavorecidos tentam, através do Poder Judiciário, realizar mudanças na estrutura arraigada de poder e, nesta tentativa, despertam a resistência daqueles que sofreriam um declínio de potestade em decorrência da alteração do status quo (MANSBRIDGE; SHAMES, 2008, p. $625)$.

A reação contrária pode vir de vários segmentos da sociedade, como, por exemplo, entidades religiosas ou partidos conservadores. Pode, inclusive, advir de dentro do próprio movimento social que em tese a decisão judicial buscou beneficiar, tendo em vista que os próprios movimentos sociais são compostos por participantes que não raramente apresentam posicionamentos divergentes a respeito de uma mesma temática (VANHALA, 2011, p. 10).

No que tange à materialização propriamente dita do backlash, observa-se que ela pode se dar a partir de protestos, negativas de funcionários públicos ou de agentes particulares em agir da forma ordenada na decisão judicial, tentativas de promover a cisão do movimento social beneficiado, censuras, discriminações e até chegar ao extremo da violência física, através da prática de linchamentos, homicídios, estupros e espancamentos (MANSBRIDGE; SHAMES, 2008, p. 625-626).

Jane Mansbridge e Shauna L. Shames explicam que o backlash normalmente é produto da ansiedade dos movimentos sociais de que as mudanças sociais ocorram numa velocidade e extensão que a sociedade como um todo não consegue ainda aceitar (2008, p. $628)$. 
Going too far, too fast é, portanto, o fator que os estudiosos acreditam ser o responsável pela forte reação contrária às decisões judiciais progressistas. Para corroborar essa afirmação, normalmente são invocadas como exemplo as decisões tomadas pela Suprema Corte Norte-Americana nos casos Brown v. Board of Education ${ }^{2}$ e Roe v. Wade R $^{3}$ a resistência social que elas provocaram.

Atribui-se o backlash delas resultante à percepção de que estas decisões judiciais não eram o veículo adequado para fomentar a transformação social, ressaltando-se a ausência de legitimidade majoritária, legitimidade esta que poderia ter sido alcançada se a temática objeto da decisão judicial tivesse sido tratada através da aprovação de uma legislação federal ou de várias legislações estaduais (MANSBRIDGE; SHAMES, 2008, p. 628).

Ademais, o fato destas decisões terem sido impostas a todos os estados da federação norte-americana de uma vez só, mesmo nos lugares em que era notória a discordância com o posicionamento da Suprema Corte, também foi responsável pela exacerbação de ânimos de parcelas da população estadounidense (MANSBRIDGE; SHAMES, 2008, p. 628) ${ }^{4}$.

Diante da possibilidade de backlash, muitos têm questionado os limites do uso do Direito como instrumento de mudança social. Tal questionamento é motivado tendo em vista que, apesar das decisões judiciais serem um meio apto a conferir ou estender direitos, a opção pela via judicial pode por muitas vezes implicar uma piora do quadro social dos representados pelos movimentos sociais que requereram tal mudança, piora esta que pode se manifestar na revogação de direitos antes reconhecidos e dos que foram atribuídos no édito judicial (CUMMINGS; NEJAIME, 2010, p. 1238) ou até na desarticulação do próprio movimento social (VANHALA, 2011, p. 34), dentre outras questões.

A proposição de que a litigância em matéria de direitos da minoria causa mais malefícios do que benefícios na busca por transformação social é chamada de tese do

\footnotetext{
${ }^{2}$ No julgamento do caso Brown v. Board of Education, a Suprema Corte Norte-Americana entendeu serem inconstitucionais as leis estaduais que estabeleciam que negros e brancos deviam frequentar escolas públicas diferentes. A decisão judicial foi uma grande vitória para o movimento dos direitos civis norte-americano.

${ }^{3} \mathrm{O}$ julgamento do caso Roe $v$. Wade teve um importante papel na luta pelo direito ao aborto. Na decisão exarada neste caso, a Suprema Corte dos Estados Unidos entendeu que a cláusula do devido processo legal prevista na $14^{\mathrm{a}}$ Emenda da Constituição concederia a mulher a escolha de abortar ou não. Contudo, a Suprema Corte não considerou que o direito ao aborto era um direito ilimitado e, sopesando esse direito com o direito do feto, decidiu que os estados poderiam regulamentar a gravidez que adentrasse o terceiro trimestre.

${ }^{4}$ É importante ressaltar aqui que apesar de boa parte da produção acadêmica a respeito do backlash ser fruto da elaboração doutrinária americana, nada impede que esse mesmo fenômeno ocorra em outros territórios, o que faz com que cada vez mais pesquisadores de outros países comecem a se importar com o tema, inclusive pesquisadores brasileiros.
} 
backlash (CUMMINGS; NEJAIME, 2010, p. 1237), também conhecida como hipótese ou narrativa do backlash.

Os mais famosos defensores da hipótese do backlash são Gerald Rosenberg e Michael Klarman. Rosenberg critica aqueles que acreditam que a reforma social pode ser alcançada por meio de ações judiciais, pautando seu argumento na falta de recursos financeiros e de mecanismos de implementação das decisões judiciais, assim como na tese do backlash (CUMMINGS; NEJAIME, 2010, p. 1318). Para o autor, seria por conta desses fatores que os tribunais não poderiam oferecer mais do que promessas e esperanças vazias (empty promises and hollow hopes) (VANHALA, 2011, p. 7).

Rosenberg questiona a fé que é depositada no Poder Judiciário, principalmente porque este vem desempenhando historicamente o papel de defensor do status quo e da distribuição desigual de poder, riqueza e privilégios (ROSENBERG, 2005, p. 797).

Outro argumento levantado pelo pesquisador contra a opção pela via judicial seria o de que ela importaria na desradicalização dos movimentos sociais, isto é, no sequestro dos movimentos sociais "por um grupo de elite, bem-educado e de advogados ricos que acriticamente acreditam que o Direito é superior à política e que acreditam que sustentar um posicionamento em um tribunal é a mesma coisa que construir e sustentar movimentos políticos" (ROSENBERG, 2008, p. 430-431).

Michael Klarman também defende que o backlash causado por decisões judiciais tidas como progressistas são um sinal de que talvez o Poder Judiciário não deveria ser a via eleita na busca por mudanças sociais. Segundo sustenta o teórico, a atuação de instituições com maior responsividade política, como os órgãos do Poder Legislativo e do Poder Executivo, não provocaria o fenômeno do backlash (POST; SIEGEL, 2007, p. 21) e, por isso, estas arenas políticas deveriam ser priorizadas pelos movimentos sociais.

O autor chega à conclusão de que o backlash é causado em parte pela publicidade que circunda as decisões das cortes, que confere mais notoriedade a assuntos polêmicos que antes passavam despercebidos por boa parte da população (KLARMAN, 2011, p. 6).

Klarman sustenta, igualmente, que o backlash muitas vezes é provocado pelas tentativas de implementar faticamente a decisão judicial proferida do que pela própria decisão em abstrato (2011, p. 7).

Outra questão interessante que o estudioso ressalta a respeito do tema é a capacidade que vitórias iniciais nas cortes têm de alterar as prioridades dos movimentos sociais, fazendo com que eles demandem determinados direitos que antes pareciam praticamente impossíveis 
de se conseguir (KLARMAN, 2011, p. 6). Neste ponto fica evidente como as decisões judiciais acabam por antecipar algumas discussões que deveriam ser travadas dentro da sociedade, dando a elas ex ante uma espécie de ponto final, o que ensejaria a demonstração de descontentamento através da mobilização social (backlash).

Os primeiros estudos a respeito da narrativa do backlash se ocuparam da análise do impacto social causado pelas decisões judiciais da Suprema Corte Norte-americana nos casos Brown v. Board of Education e Roe v. Wade. Mais recentemente, ampliou-se o uso da hipótese do backlash para descrever também os resultados políticos das decisões de cortes estaduais dos Estados Unidos que reconheceram a possibilidade de casamento entre pessoas do mesmo sexo, em especial em relação às decisões proferidas nos casos Baehr v. Lewin ${ }^{5}$ e Goodridge v. Department of Public Health ${ }^{6}$, respectivamente, pela Suprema Corte do Havaí e pela Suprema Corte de Massachusetts.

Gerald Rosenberg consignou que estas duas decisões judiciais mencionadas geraram contramobilizações políticas que levaram à aprovação de leis e emendas constitucionais a nível estadual e federal que visavam impedir o casamento homoafetivo, isto é, ao invés de ajudarem na conquista do direito ao casamento homoafetivo acabaram por criar mais barreiras a sua aprovação (CUMMINGS; NEJAIME, 2010, p. 1243).

A título exemplificativo, Rosenberg cita como backlash resultante da decisão do caso Baehr v. Lewin a promulgação do Defense of Marriage Act, também conhecido como DOMA, lei federal que determinou que o governo federal apenas consideraria como casamento a união entre um homem e uma mulher e que nenhum estado da federação era obrigado a reconhecer um casamento homoafetivo realizado em outro estado, mesmo que em conformidade com as leis deste outro estado. Outra consequência que denotaria o backlash provocado por esta decisão seria a aprovação popular de uma emenda à Constituição do Havaí que instituiu a proibição de casamentos entre pessoas do mesmo sexo.

O backlash causado pela decisão judicial expedida no caso Goodridge v. Department of Public Health, por sua vez, ocasionou a alteração da redação das Constituições de 11

\footnotetext{
${ }^{5}$ No caso Baehr v. Board of Education, a Suprema Corte do Estado do Havaí julgou que a proibição de realização de casamentos homoafetivos violava a Constituição Estadual. Foi uma das primeiras decisões a reconhecer o direito de pessoas do mesmo sexo de contraírem matrimônio.

${ }^{6} \mathrm{O}$ caso Goodrige v. Department of Public Health foi outro caso paradigmático na luta pela legalização do casamento homoafetivo, tendo em vista que foi a primeira vez que uma das cortes mais elevadas dos Estados Unidos reconheceu que pessoas homossexuais tinham o direito de poderem se casar.
} 
estados norte-americanos para que o casamento passasse a ser definido expressamente como a união entre um homem e uma mulher. Rosenberg chega inclusive a afirmar que o backlash provocado pelo pronunciamento do Poder Judiciário do Estado de Massachusetts teria tido impacto no desempenho do Partido Democrata nas eleições de 2004 e até mesmo na corrida presidencial (JONES, 2014, p. 14-15).

Entretanto, apesar da hipótese do backlash ser muito bem construída, como se pode comprovar com a breve explanação realizada, verifica-se que ela possui algumas limitações que merecem ser apontadas.

Em primeiro lugar, a tese do backlash trata os advogados e integrantes dos movimentos sociais como atores sociais ingênuos que depositam todas as suas esperanças nas cortes de justiça, quando em verdade a esfera judicial é apenas uma das frentes em que se travam as batalhas para a efetivação de mudanças sociais e que é utilizada de forma extremamente estratégica.

Outro ponto que é desconsiderado pelos defensores da narrativa do backlash é que, apesar das consequências negativas que uma decisão judicial tida como progressista pode ter, ela também muitas vezes representa grandes avanços a causa encampada pelo movimento social que visou beneficiar.

É igualmente questionável a argumentação que sustenta que se a mesma medida fosse tomada por outros meios, como, por exemplo, a promulgação de uma lei ou plebiscito, evitaria a materialização do backlash, já que nada impede que setores da sociedade também se mobilizem contra a imposição de vontade divergente a sua, mesmo que majoritária.

Por fim, a hipótese do backlash parece ser construída em cima de uma noção de um devir inevitável de uma sociedade melhor e mais progressista, que não deixa de ser uma visão extremamente romantizada da sociedade e que desconsidera a sua dinamicidade.

Tais limitações podem ser facilmente vislumbradas a partir do exemplo paradigmático da litigância em matéria de casamento entre pessoas do mesmo sexo nos Estados Unidos, que culminou recentemente no reconhecimento do direito fundamental ao casamento para casais homoafetivos pela Suprema Corte Americana no caso Obergefell v. Hodges, motivo pelo qual este trabalho analisará as limitações da hipótese do backlash a partir da ótica da litigância em prol do casamento entre pessoas homossexuais. 


\section{ESTRATÉGIA DA DUAL TRACK ADVOCACY - INFLUÊNCIA DA PERSPECTIVA DO BACKLASH NA JUDICIALIZAÇÃO DA DEMANDA DO CASAMENTO HOMOAFETIVO}

A relação dinâmica entre Direito e mudança social é protagonizada por diversos atores sociais, merecendo destaque a atuação dos movimentos sociais. Tal conclusão é possível, conforme explicita Lisa Vanhala, pelo fato de que os movimentos sociais solicitam mudanças não só na política, mas também nas formas de se encarar o mundo e viver, o que inevitavelmente acaba por criar novas demandas legais (2011, p. 4-5). A partir disso, é possível vislumbrar o importante papel que estes atores desempenham na construção discursiva do Direito, principalmente através da propositura de ações judiciais e da atuação a título de amicus curiae (VANHALA, 2011, p. 4-5).

Tommaso Pavone, por sua vez, acredita que a estreita relação entre movimentos sociais e o Direito é provocada pelo fato de que o discurso jurídico é a linguagem do status quo e que os movimentos sociais optam por fazer uso deste código de linguagem visando diminuir a resistência que sofrem por parte dos setores mais conservadores da sociedade (2014, p. 4). Dito de outra forma, o uso de um discurso técnico e tradicional - como o é o discurso do Direito - afasta a imagem de radicalismo que poderia ser associada a esses movimentos e faz com que atores políticos importantes passem a ouvir suas demandas e até mesmo defendê-las.

Apesar de ser inegável, portanto, a estreita relação entre os movimentos sociais e o Direito, não é possível afirmar, como parecem o fazer os defensores da hipótese do backlash, que estes movimentos têm total controle sobre as demandas relacionadas à sua causa que chegam aos tribunais ou que não se preocupam com alternativas não-jurídicas para buscar as mudanças sociais almejadas.

Em verdade, é justamente o contrário. Os advogados que representam os movimentos sociais são agentes políticos sofisticados que atuam com destreza num campo extremamente complexo devido à multiplicidade de atores que devem ser persuadidos e às inúmeras escolhas estratégicas que podem ser feitas.

Além disso, a opção pela busca judicial dos direitos não é uma escolha óbvia como querem fazer crer. Muitas vezes o papel do advogado que atua representando movimentos sociais é o de fazer lobby pressionando políticos e o de incitar apoio por parte da população à 
causa, uma atividade que de jurídica quase não tem nada. Para estes advogados, as cortes são apenas mais uma alternativa na luta pela mudança social e não as grandes salvadoras dos desfavorecidos. É por isso que a litigância em prol de movimentos sociais é vista como multidimensional (CUMMINGS; NEJAIME, 2010, p. 1242).

O caráter multidimensional desta espécie de litigância é motivado, em grande parte, pela preocupação com a possibilidade de resistência política que uma vitória judicial pode provocar - a possibilidade de backlash.

Essa preocupação encontra lugar principalmente na busca judicial pelo reconhecimento do direito ao casamento homoafetivo. Segundo Beth Robinson, uma das principais advogadas que atuou no caso paradigmático Baker v. State of Vermont ${ }^{7}$, seria justamente a capacidade de antecipação da resistência que as decisões judiciais poderiam incitar o que diferenciaria a advocacia em prol do casamento entre pessoas do mesmo sexo da litigância das demais causas sociais (JONES, 2014, p. 85).

Muito embora a apreensão com os efeitos nocivos que uma vitória judicial possa gerar esteja presente em cada caso apresentado perante os tribunais, muitos advogados que defendem o direito ao casamento homoafetivo relutam em adotar o termo backlash para descrever a mobilização política que uma manifestação judicial pode ensejar (JONES, 2014, p. 83-84). Aqueles que partilham deste entendimento argumentam, na esteira do que Martin Luther King Jr. uma vez disse, que, em verdade, o que se vislumbraria seria um lashing, isto é, a continuidade, ainda que com um acréscimo de intensidade e/ou visibilidade, de ideias e de políticas que já se faziam presentes antes mesmo de qualquer vitória judicial ${ }^{8}$.

De todo modo, é inegável que a preocupação com uma possível reação social que minasse todas as conquistas já alcançadas pelo movimento social era constante dentre aqueles responsáveis pela defesa judicial do casamento homoafetivo. Tanto o é que não foram eles quem propuseram a ação judicial que levou a primeira vitória na matéria (caso Baehr v. Lewin).

\footnotetext{
${ }^{7}$ A Suprema Corte do Estado de Vermont, ao analisar o caso Baker v. State of Vermont, decidiu que a legislação estadual que vedava a possibilidade de casamento entre pessoas do mesmo sexo violava direitos garantidos pela Constituição do Estado de Vermont e, por isso, não merecia subsistir. Aquela corte determinou, ainda, que o órgão legislativo estadual implementasse um mecanismo legal que concedesse aos casais homoafetivos direitos similares aos concedidos a casais heterossexuais.

${ }^{8}$ Martin Luther King Jr. acreditava que o uso da expressão backlash não era adequado, já que ele dava a impressão de que a nação tinha decidido que ia resolver um problema e que por conta do movimento dos direitos civis se retrocedeu nesse sentido. Para ele o suposto backlash causado pelo movimento dos direitos civis seria apenas uma maior visibilidade dos preconceitos que já existiam. (JONES, 2014, p. 88).
} 
Ao contrário do que os partidários da hipótese do backlash parecem sugerir, o movimento social, mesmo na condição de principal defensor de uma determinada causa, não tem como ter controle sobre quem entra ou não com uma ação judicial.

O máximo que seus participantes podem fazer é tentar dissuadir eventuais proposituras de ação e, se isso não for possível, entrar no processo judicial como parte assistente ou na condição de amicus curiae, assim como ajudar os advogados que entraram com a causa a preparar de forma mais adequada os argumentos legais a serem expostos.

No caso Baehr v. Lewin, uma vez proposta a ação, os movimentos sociais não tiveram outra escolha senão enviar um de seus advogados para atuar como assistente e cumprir este papel de auxílio. O advogado que acabou exercendo essa função foi Evan Wolfson.

Evan Wolfson, fundador da organização social Freedom to Marry e advogado assistente no já citado caso Baehr v. Lewin, é tido como o principal responsável pelo que se convencionou chamar dual track advocacy, que seria uma litigância que se preocupa não apenas com as questões legais dos pedidos judiciais de reconhecimento do direito ao casamento homoafetivo, mas também com as questões políticas que circundam as ações judiciais que demandam este direito (JONES, 2014, p. 57).

Wolfson explicou em uma entrevista concedida à revista The Atlantic Monthly que elaborou a dual track advocacy após estudar o caso Loving v. Virginia, caso em que a Suprema Corte Norte-Americana decidiu serem inválidas todas as leis que proibiam casamentos interraciais. $\mathrm{O}$ advogado esclareceu que à época em que a decisão foi proferida $70 \%$ dos norte-americanos acreditavam que pessoas de diferentes raças não deveriam se casar entre si, porém 34 estados da federação reconheciam essa possibilidade. Diante disso, Wolfson percebeu que uma boa estratégia para levar a discussão do casamento homoafetivo até a Suprema Corte dos Estados Unidos seria combinando vitórias judiciais a nível estadual e apoio por parte da população norteamericana ${ }^{9}$.

O caso Baehr v. Lewin foi um exemplo de vitória judicial em nível estadual, no entanto os movimentos sociais relacionados à causa do casamento homoafetivo não tiveram muitos motivos para comemorar porque na sequência foi aprovado o Defense of Marriage Act (DOMA), ato normativo que expressamente consignou que o governo federal não reconheceria como válido nenhum casamento entre pessoas do mesmo sexo, mesmo que esse

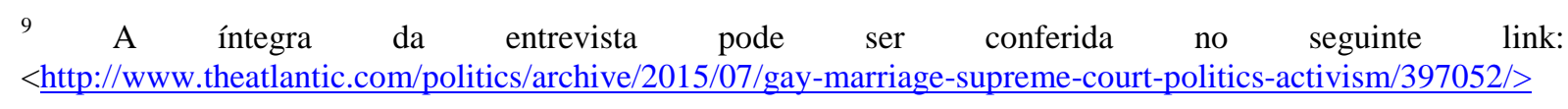


matrimônio tivesse sido contraído de acordo com as exigências legais estabelecidas pelo estado da federação em que foi realizado.

Em face dessa vitória inicial, mas principalmente em face do desastroso revés, os advogados entenderam que a litigância em nível estadual deveria ser realizada em estados em que a população apoiasse o movimento LGBT e que a constituição estadual fosse difícil de ser alterada (CUMMINGS; NEJAIME, 2010, p. 1254). No entanto, estudar quais estados atendiam a essas exigências não seria suficiente, era também necessário preparar o terreno político para evitar que o backlash colocasse em risco qualquer vitória judicial conquistada.

O primeiro estado escolhido para se entrar com uma ação judicial propugnando o reconhecimento do casamento homoafetivo foi Vermont, escolha que se mostrou acertada no julgamento do caso Baker v. Vermont, pois na ocasião foi afirmado o direito que casais do mesmo sexo tinham de contrair matrimônio. Na sequência, foram propostas ações nos estados de Massachusetts e New Jersey que igualmente tiveram resultados positivos. Necessário ressaltar que nos três casos as vitórias judiciais, devido à utilização da dual track advocacy, sobreviveram ao backlash por elas causado (KECK, 2009, p. 177).

A estratégia elaborada por Wolfson se mostrou bem-sucedida e atingiu a sua expectativa de conseguir que a Suprema Corte Norte-Americana reconhecesse, no caso Obergefell $v$. Hodges, que o direito ao casamento era garantido a casais do mesmo sexo tanto pela cláusula do devido processo legal quanto pela cláusula da igual proteção, ambas presentes na $14^{\mathrm{a}}$ Emenda à Constituição Estadunidense.

Diante do exposto, mais não resta do que concluir que as organizações e movimentos sociais em prol do casamento homoafetivo internalizaram a hipótese do backlash ao demonstrar uma especial preocupação com os aspectos políticos de todos os casos que levavam às cortes a fim de conseguir e proteger eventuais vitórias legais, o que demonstraria que, ao contrário do que querem fazer crer os defensores da tese do backlash, a litigância não foi a única via eleita, mas apenas um dos caminhos encontrados e trilhados na luta pelo reconhecimento deste direito, caminho que se mostrou extremamente frutífero com a recente decisão da Suprema Corte Norte-Americana no caso Obergefell v. Hodges.

\section{REAVALIANDO O BACKLASH - DISSENSO COMO CONDIÇÃO FUNDAMENTAL PARA O FORTALECIMENTO DA DEMOCRACIA E DA ORDEM CONSTITUCIONAL}


Como demonstrado no tópico anterior, a hipótese do backlash falha ao partir da premissa de que o backlash seria causado pelo foco exclusivo dos movimentos sociais na via judicial, premissa essa que não se confirma na prática, conforme ilustrado através do exemplo da litigância coordenada pelo movimento LGBT em prol do casamento homoafetivo.

Entretanto, não é somente em relação a este tocante que a narrativa do backlash apresenta algumas inconsistências. A produção acadêmica relativa a esta tese parte de outras duas premissas extremamente questionáveis: a de que se a mesma decisão fosse atingida através de outras vias o blacklash não ocorreria e a de que a mera possibilidade de ocorrência do backlash seria argumento suficiente para que os movimentos sociais deixassem de buscar mudanças sociais através das cortes de justiça (CUMMINGS; NEJAIME, 2010, p. 1244).

Reva Siegel e Linda Greenhouse afirmam que em primeiro lugar deveria ser questionada essa premissa de que as decisões judiciais provocam, no geral, reações políticas mais hostis do que, por exemplo, legislações que instituem os mesmos direitos (2013, p. 245246).

Segundo as autoras, existe e continuará existindo conflitos a respeito de temas politicamente sensíveis como aborto, casamento homoafetivo e o próprio significado da igualdade. Por isso, para elas, qualquer tentativa de alterar o status quo e de reivindicar direitos para segmentos desfavorecidos da sociedade - seja em cortes, em câmaras de deputados e no senado, ou até mesmo nas urnas - muito provavelmente gerará conflitos que podem, inclusive, produzir o fenômeno do backlash (GREENHOUSE; SIEGEL, 2013, p. 245-246).

Thomas M. Keck, a seu turno, sustenta que, mesmo quando as alterações do status quo se dão através da promulgação de legislações em níveis estaduais, há a ocorrência reações sociais semelhantes às que usualmente eram provocadas por decisões judiciais tidas por progressistas.

A título exemplificativo, Keck cita a promulgação no estado de Oregon de leis que proibiam a discriminação baseada na orientação sexual e que reconheciam a possibilidade de aplicação do instituto da domestic partnership (algo parecido com o que é conhecido aqui no ordenamento jurídico brasileiro por união estável) a casais do mesmo sexo.

A reação a essas legislações foi tamanha que, logo após a entrada em vigor destas disposições legais, setores contrários a estas leis tentaram convocar um plebiscito para colocá- 
las sobre o escrutínio popular e talvez assim extirpá-las do ordenamento jurídico. Para conseguir convocar o plebiscito precisavam de um número significativo de assinaturas, tarefa que não conseguiram realizar segundo a Suprema Corte do Estado de Oregon (KECK, 2009, p. 181) e por isso fracassaram nesta empreitada.

Diante desta contestação - de que todas as vitórias do movimento LGBT incitaram mobilizações contrárias, independentemente se essas vitórias se deram através do Poder Legislativo, Executivo ou Judiciário - o pesquisador concluiu que evitar a via judicial não garantiria que o fenômeno do backlash não iria acontecer (KECK, 2009, p. 181), motivo pelo qual a hipótese do backlash não mereceria credibilidade.

Outra crítica que merece ser tecida contra a hipótese do backlash diz respeito à pressuposição a ela inerente de que este fenômeno é em sua totalidade negativo, quando, em verdade, é possível verificar aspectos positivos derivados de sua ocorrência. Novamente, a litigância em prol do casamento homoafetivo pode ser usada como exemplo.

A maioria dos advogados que atuam em favor da promoção da legalização do casamento homoafetivo reconhecem que mesmo quando perdem um caso judicial, o movimento social é muitas vezes beneficiado por esta derrota, já que casos relativos a temas politicamente sensíveis normalmente ganham muita publicidade (JONES, 2014, p. 101).

A este respeito, James Esseks, diretor da ACLU Lesbian Gay Bixesual Transgender \& AIDS Project, comenta que o movimento pró-casamento homoafetivo tenta conseguir a atenção das pessoas para explicar para elas o porquê das pessoas homossexuais desejarem tanto poderem se casar e que todos os casos julgados pelas cortes, independente se resultaram em vitórias ou não, permitiram essa conversa devido à publicidade que recebem (JONES, 2014, p. 102). É com base nisso que se defende que mesmo as derrotas judiciais propiciam avanços na temática do casamento igualitário.

Assim como as derrotas judiciais sofridas pelos defensores do casamento entre pessoas do mesmo sexo tiveram implicações positivas, o backlash decorrente de algumas decisões judiciais também ajudou a fortalecer o movimento LGBT em sua busca pelo reconhecimento desta modalidade de casamento.

Outro exemplo notório de backlash na história jurídico-legal dos Estados Unidos diz respeito ao que se chamou de Proposition 8 e demonstra exatamente esse aspecto positivo que pode resultar das mobilizações sociais reacionárias.

A proposta surgiu como uma reação contrária à decisão judicial exarada nos In Re Marriage Cases julgados pela Suprema Corte do Estado da Califórnia, decisão esta que havia 
reconhecido que a existência de legislação que limitava o casamento a casais de sexos opostos violava os direitos de casais homoafetivos. Sua redação previa que o Estado da Califórnia somente reconheceria como válidos os casamentos entre um homem e uma mulher.

Muito embora a aprovação da Proposta 8 fosse inegavelmente um retrocesso na luta pela legalização do casamento homoafetivo, a campanha utilizada pelos opositores do matrimônio entre pessoas do mesmo sexo serviu para demonstrar os ataques e preconceitos a que pessoas homossexuais estavam sujeitas, explicitando a monstruosidade da homofobia, abrindo os olhos de muitas pessoas de fora do movimento social que não tinham consciência de como o preconceito poderia chegar a níveis tão hostis e violentos e explicitando o impacto disso na vida de outros seres humanos (JONES, 2014, p. 103).

Serviu igualmente para evidenciar a necessidade de pessoas LGBT de se unirem e se organizarem a fim de demandarem seus direitos, o que acabou por inegavelmente fortalecer o movimento LGBT (JONES, 2014, p. 104).

Quanto a Proposta 8 cumpre esclarecer que ela acabou sendo aprovada em 2008, entretanto, foi julgada inconstitucional em 2010 por uma corte federal, deixando de produzir efeitos jurídicos apenas em 2013 quando a decisão finalmente transitou em julgado.

Os efeitos positivos que a ocorrência do backlash pode provocar, entretanto, não se restringem aos movimentos sociais.

Robert Post e Reva Siegel são exemplos de autores que reconhecem a perspectiva positiva que o backlash pode ter na sociedade em geral, realizando a análise do fenômeno a partir do marco teórico do constitucionalismo democrático.

Post e Siegel explicam que a teoria do constitucionalismo democrático interpreta o dissenso como uma condição inerente ao desenvolvimento do direito constitucional, tendo em vista que vários direitos constitucionalmente consagrados foram estabelecidos em meio a um contexto cultural de controvérsia (2007, p. 4).

A corrente teórica do constitucionalismo democrático entende o backlash, enquanto manifestação do dissenso, como uma das muitas formas de contestação através das quais a população procura influenciar a construção do direito constitucional (POST; SIEGEL, 2007, p. 11). Partindo dessa premissa, é possível identificar como o backlash pode servir como instrumento de promoção de solidariedade e fortalecimento da legitimação democrática das interpretações constitucionais (POST; SIEGEL, 2007, p. 4). 
Post e Siegel argumentam que quando cidadãos invocam a Constituição como fundamento para criticar decisões judiciais, eles estão expressando seu descontentamento com o governo ao mesmo tempo em que reforçam a sua identificação com a tradição constitucional, fato que pode implicar no fortalecimento da coesão social e na atribuição de legitimidade constitucional às decisões do Estado, independentemente do Poder de onde foram emanadas (2007, p. 35-36).

É essa demonstração de comprometimento com o significado da Constituição que faz com que os adeptos do constitucionalismo democrático vejam as controvérsias provocadas por decisões judiciais como algo positivo para o fortalecimento da ordem constitucional (POST; SIEGEL, 2007, p. 19) e não como um fenômeno exclusivamente negativo.

Parte dessa concepção de que o backlash é uma ameaça ao funcionamento ordinário do jogo democrático vem da noção de supremacia e ativismo judicial, em que normalmente se prega que as cortes devam ter a última palavra em matéria constitucional. Contudo, conforme é sustentado pelos defensores do constitucionalismo democrático, nenhuma dos ramos do poder, incluindo o judicial, devem ter o monopólio de precisar o significado definitivo da constituição.

A interpretação constitucional realizada pelas Supremas Cortes é apenas uma das vozes - não a única nem necessariamente a principal - no diálogo que busca estabelecer o significado da Constituição.

Desta forma, seria impossível negar que o backlash tem esse sentido positivo de mobilizar a sociedade civil, de fazer com que ela defenda as suas interpretações constitucionais e participe ativamente na construção destas, mesmo que muitas vezes essas posições sejam contrárias ao senso comum da razão técnico-legal.

Aqueles que defendem a hipótese do backlash parecem se pautar pela noção de um devir inevitável de uma sociedade melhor e mais progressista, desconsiderando a dinamicidade inerente ao desenvolvimento dos agrupamentos humanos. É por isso que interpretam a realidade de uma forma binária, em que todo avanço é tido como uma coisa exclusivamente boa e todo retrocesso como intrinsecamente ruim.

No entanto, não é assim que democracias funcionam.

\section{CONCLUSÃO}


O presente trabalho pretendeu repensar a relação entre Constitucionalismo e Democracia a partir da dinâmica estabelecida entre Direito, movimentos sociais e transformação social. Para tanto, buscou-se analisar de forma crítica o fenômeno do backlash: a tese de que a judicialização de questões sociais consideradas como politicamente sensíveis poderia ser mais prejudicial do que benéfica à causa que se pretendia defender.

Foi identificado que, ao contrário do que a maioria dos teóricos que se dedicam ao estudo da hipótese do backlash sustenta, a opção feita pelos movimentos sociais de recorrer à judicialização sempre é muito bem calculada. $\mathrm{O}$ que se observou é que os movimentos sociais ao adotarem a linguagem do status quo - a linguagem jurídica - demonstraram serem atores políticos de extrema habilidade e não atores sociais ingênuos como querem fazer crer os defensores da narrativa do backlash.

Este artigo demonstrou esse refinamento estratégico desenvolvido pelos movimentos sociais utilizando como exemplo a litigância em favor do reconhecimento legal do casamento homoafetivo empreendida nos Estados Unidos.

A escolha deste caso em específico foi motivada pelo fato de que os defensores do casamento igualitário estruturaram toda a sua atuação judicial e política de modo a evitar - ou pelo menos diminuir a intensidade - do backlash, demonstrando que é possível conseguir avanços através da via judicial, desde que não se deixasse de lado outras medidas de caráter político. Isto é, este caso é o exemplo emblemático de como a litigância estratégica em matéria de direitos humanos não desconsidera a hipótese do backlash, pelo contrário, a internalizou e, por isso, se mostrou bem sucedida.

Nesse sentido, como primeira conclusão, evidenciou-se a falácia da acusação de que a litigância em matéria de questões sociais sensíveis desconsidera a possibilidade de um efeito social prejudicial à própria causa pela qual se litiga.

Em um segundo momento, foi proposta uma nova forma de se conceber o dissenso, mesmo que em forma de backlash. Partindo dessa premissa, defendeu-se que é errôneo pressupor o backlash como um fenômeno exclusivamente nocivo às causas dos movimentos sociais, uma vez que, por muitas vezes, ele serve para dar mais visibilidade às bandeiras levantadas por estes e aumentar a coesão social em torno de uma busca por mudanças sociais, além de também ajudar no fortalecimento tanto da democracia quanto da ordem constitucional. 
A segunda proposição deste trabalho é a de que avanços e retrocessos fazem parte do jogo democrático, fazem parte da tensão existente entre Constitucionalismo e Democracia, já que não existe um caminho linear que leva a um devir inevitável de uma sociedade melhor e mais progressista, sendo o backlash apenas mais uma parte desta disputa.

\section{REFERÊNCIAS BIBLIOGRÁFICAS}

BALL, Carlos A., The Backlash Thesis and Same-Sex Marriage: Learning from Brown v. Board of Education and its Aftermath. William \& Mary Bill of Rights Journal, v. 14, 2006. Disponível em: <http://ssrn.com/abstract=901238>. Acesso em 17 de novembro de 2015.

CUMMINGS, Scott L.; NEJAIME, Douglas. Lawyering for marriage equality. UCLA Law Review, v. 57, 2010. Disponível em: <http://www.uclalawreview.org/lawyering-for-marriageequality/>. Acesso em: 19 de novembro de 2015.

GREENHOUSE, Linda; SIEGEL, Reva. Backlash to the future? From Roe to Perry. UCLA Law Review Discourse, v. 60, 2013. Disponível em:

$<$ http://www.uclalawreview.org/pdf/discourse/60-17.pdf>. Acesso em: 19 de novembro de 2015.

JONES, Alexander Wade. Dual track advocacy: legal strategies, political strategies and their intersection in the marriage equality movement. UVM Honors College Senior Thesis, Paper 14, 2014. Disponível em: < http://scholarworks.uvm.edu/cgi/viewcontent.cgi?article=1041\&context=hcoltheses $>$. Acesso em: 8 de novembro de 2014 .

KECK, Thomas M. Beyond backlash: assessing the impact of judicial decisions on LGBT rights. Law and Society Review, v. 43, 2009. Disponível em: < http://papers.ssrn.com/sol3/papers.cfm?abstract_id=1839439>. Acesso em: 17 de novembro de 2015 .

KLARMAN, Michael. Courts, social change and political backlash. Philip A. Hart Lecture. Georgetown Law Centre, em 31 de março de 2011. Disponível em: < 
http://scholarship.law.georgetown.edu/cgi/viewcontent.cgi?article=1001\&context=hartlecture >. Acesso em: 7 de novembro de 2015.

MANSBRIDGE, Jane; SHAMES, Shauna L. Toward a theory of backlash: dynamic resistance and the central role of power. Politics \& Gender Journal, 2008. Disponível em: < http://scholar.harvard.edu/shaunashames/publications/toward-theory-backlash-dynamicresistance-and-central-role-power>. Acesso em: 23 de novembro de 2015.

OLIVEIRA, Larissa Pinha de; OLIVEIRA, Fábio Corrêa Souza de. Abrindo, lendo e escrevendo as páginas do romance em cadeia: diálogos, backlash e hermenêutica. JurisPoiesis. Rio de Janeiro: Editora CRV, n. 14, p. 103-132, 2011.

OXFORD DICTIONARY. Backlash definition. Disponível em: $<$ http://www.oxforddictionaries.com/pt/defini\%C3\%A7\%C3\%A3o/ingl\%C3\%AAs/backlash? searchDictCode=all> . Acesso em: 17 de novembro de 2015.

PAVONE, Tommaso. Beyond the hollow hope: the promise and challenges of studying gradual sociolegal change. Publicado em 7 de dezembro de 2014. Disponível em: $<$ http://tommasopavone.yolasite.com/resources/Rosenberg\%20The\%20Hollow\%20Hope\%20(Critical\%20Review).pdf>. Acesso em: 22 de outubro de 2015.

POST, Robert; SIEGEL, Reva. Roe Rage: Democratic Constitutionalism and Backlash. Harvard Civil Rights-Civil Liberties Law Review, 2007; Yale Law School, Public Law Working Paper No. 131. Disponível em: 〈http://ssrn.com/abstract=990968 >. Acesso em: 19 de outubro de 2015.

ROSENBERG, Gerald. Courting Disaster: looking for change in all the wrong places. Drake Law Review, v. 54, 2005. Disponível em: <

$\underline{\text { http://chicagounbound.uchicago.edu/cgi/viewcontent.cgi?article=2922\&context=journal_artic }}$ les>. Acesso em: 19 de outubro de 2015. 
The Hollow Hope: can courts bring about social change? rev. ed. Chicago: University of Chicago Press, 2008.

VALLE, Vanice Regina Lírio do. Backlash à decisão do Supremo Tribunal Federal: pela naturalização do dissenso como possibilidade democrática. Palestra proferida no II Seminário Internacional da Teoria das Instituições. Universidade Federal do Rio de Janeiro, novembro de 2013. Disponível em: <

https://www.academia.edu/5159210/Backlash_\%C3\%A0_decis\%C3\%A3o_do_Supremo_Tri bunal_Federal_pela_naturaliza\%C3\%A7\%C3\%A3o_do_dissenso_como_possibilidade_demo cr\%C3\%A1tica>. Acesso em: 17 de novembro de 2015.

VANHALA, Lisa. Social movements lashing back: law, social change and socio-legal backlash in Canada. Studies in Law, Politics and Society, v. 54, 2011. Disponível em: <http://papers.ssrn.com/sol3/papers.cfm?abstract_id=1643576>. Acesso em: 23 de novembro de 2015. 